\title{
Analisis Volume Sedimen Berdasarkan Hasil Pengukuran Dengan Echosounder Dalam Waduk Bili-bili Kabupaten Gowa
}

\author{
Elisa Trinofri Sanjaya ${ }^{\star 1}$, Melly Lukman ${ }^{\star 2}$, Benyamin Tanan ${ }^{\star 3}$ \\ *1 Mahasiswa Program Studi Teknik Sipil, Universitas Kristen Indonesia Paulus, Makassar, Indonesia \\ elisasanjaya@gmail.com
}

\author{
*2*3 Dosen Program Studi Teknik Sipil, Universitas Kristen Indonesia Paulus, Makassar, Indonesia \\ novi wre@yahoo.co.id dan nyamintan2002@yahoo.com
}

\begin{abstract}
ABSTRAK
Waduk Bili-Bili, Kabupaten Gowa, Provinsi Sulawesi Selatan merupakan waduk serbaguna yang dibangun pada tahun 1994. Waduk Bili-bili dibangun dengan tujuan untuk mengoptimalkan pengelolaan dan pemanfaatan sumber daya air, serta untuk mencegah banjir di musim hujan. Dalam perkembangannya telah terjadi penurunan pemanfaatan fungsi layanan waduk akibat adanya sedimen dalam waduk. Dari hasil pengukuran pada tahun 2017, pada elevasi $+99.5 \mathrm{~m}$ (muka air normal), kapasitas waduk berkurang dari 347.81 juta m3 menjadi 239.76 juta m3 selama 20 tahun akibat banyaknya sedimen dalam Waduk Bili-bili. Total volume sedimen dari tahun $1997-2017$ sebanyak 108.050 juta m3. Jika hal ini terus berlanjut, maka sisa usia guna Waduk Bili-bili tidak akan efektif. Tujuan dari penelitian ini adalah untuk mengetahui besar volume sedimen yang ada dalam Waduk Bili-bili, Kabupaten Gowa, Provinsi Sulawesi Selatan pada tahun 2019. Penelitian ini adalah pengukuran di lapangan dengan menggunakan alat Echosounder dan pengumpulan data sekunder berupa: Peta Kontur Waduk Bili-bili Tahun 1997. Dari hasil pengukuran Echosounder dibuat peta kontur dasar Waduk Bili-bili tahun 2019 dengan peta waduk tahun 1997 dan dibuat potongan-potongan melintang sebagai dasar perhitungan volume sedimen. Berdasarkan hasil penelitian dan perhitungan, total volume sedimen dalam waduk Bili-bili dari tahun 1997 - 2019 sebanyak 110.371 juta m3 dan pada pengukuran tahun 2017 total volume sedimen hanya sebanyak 108.050 juta $\mathrm{m}^{3}$. Sehingga total laju sedimen pada tahun 2017 sampai tahun 2019 sebanyak 2.321 juta $\mathrm{m}^{3}$.
\end{abstract}

Kata Kunci : Echosounder, volume sedimen, waduk

\begin{abstract}
The Bili-Bili Reservoir, Gowa Regency, South Sulawesi Province is a multipurpose reservoir built-in 1994. The Bili-Bili Reservoir was built with the aim of the management and utilization of water resources, as well as to prevent flooding in the rainy season. During its development, there has been a decline in the use of the reservoir service function due to the presence of sediment in the reservoir. From the results of measurements in 2017, at an elevation of $+99.5 \mathrm{~m}$ (normal water level), the reservoir capacity decreased from 347.81 million $\mathrm{m} 3$ to 239.76 million $\mathrm{m} 3$ over 20 years due to a large amount of sediment in the Bili-Bili Reservoir. The total volume of sediment from 1997- 2017 was 108,050 million m3. If this continues, the remaining useful life of the Bili-Bili Reservoir will not be effective. The purpose of this study is to determine the volume of sediment in the Bili-Bili Reservoir, Gowa Regency, South Sulawesi Province in 2019. This research is a field measurement using an Echosounder and secondary data collection in the form of a contour map of the Bili-Bili Reservoir. 1997. From the results of Echosounder measurements, a basic contour map of the Bili-Bili Reservoir in 2019 was made with the 1997 reservoir map, and cross-sections were made as to the basis for calculating the volume of sediment. Based on the results of research and calculations, the total volume of sediment in the Bili-Bili reservoir from 1997 to 2019 was 110,371 million $\mathrm{m} 3$ and in 2017 the total volume of sediment was only 108,050 million $\mathrm{m}^{3}$. The total sediment rate in 2017 to 2019 is 2,321 million $\mathrm{m}^{3}$.
\end{abstract}

Keywords: Echosounder, volume, sediment, reservoir.

\section{PENDAHULUAN}

Waduk Bili-Bili, Kabupaten Gowa, Provinsi Sulawesi Selatan merupakan waduk serbaguna yang dibangun pada tahun 1994, dengan tinggi bendung utama $73 \mathrm{~m}$, panjang $750 \mathrm{~m}$, lebar puncak $10 \mathrm{~m}$ dan elevasi puncak $+106 \mathrm{~m}$. Waduk
Bili-bili memiliki daerah tangkapan $384,40 \mathrm{~km}^{2}$, kapasitas tampungan 375 juta $\mathrm{m}^{3}$, kapasitas tampungan efektif 347 juta $\mathrm{m}^{3}$ dan volume tampungan sedimen 29 juta $\mathrm{m}^{3}$. Waduk Bili-bili dibangun dengan tujuan untuk mengoptimalkan pengelolaan dan pemanfaatan sumber daya air, serta untuk mencegah banjir jika musim hujan. 


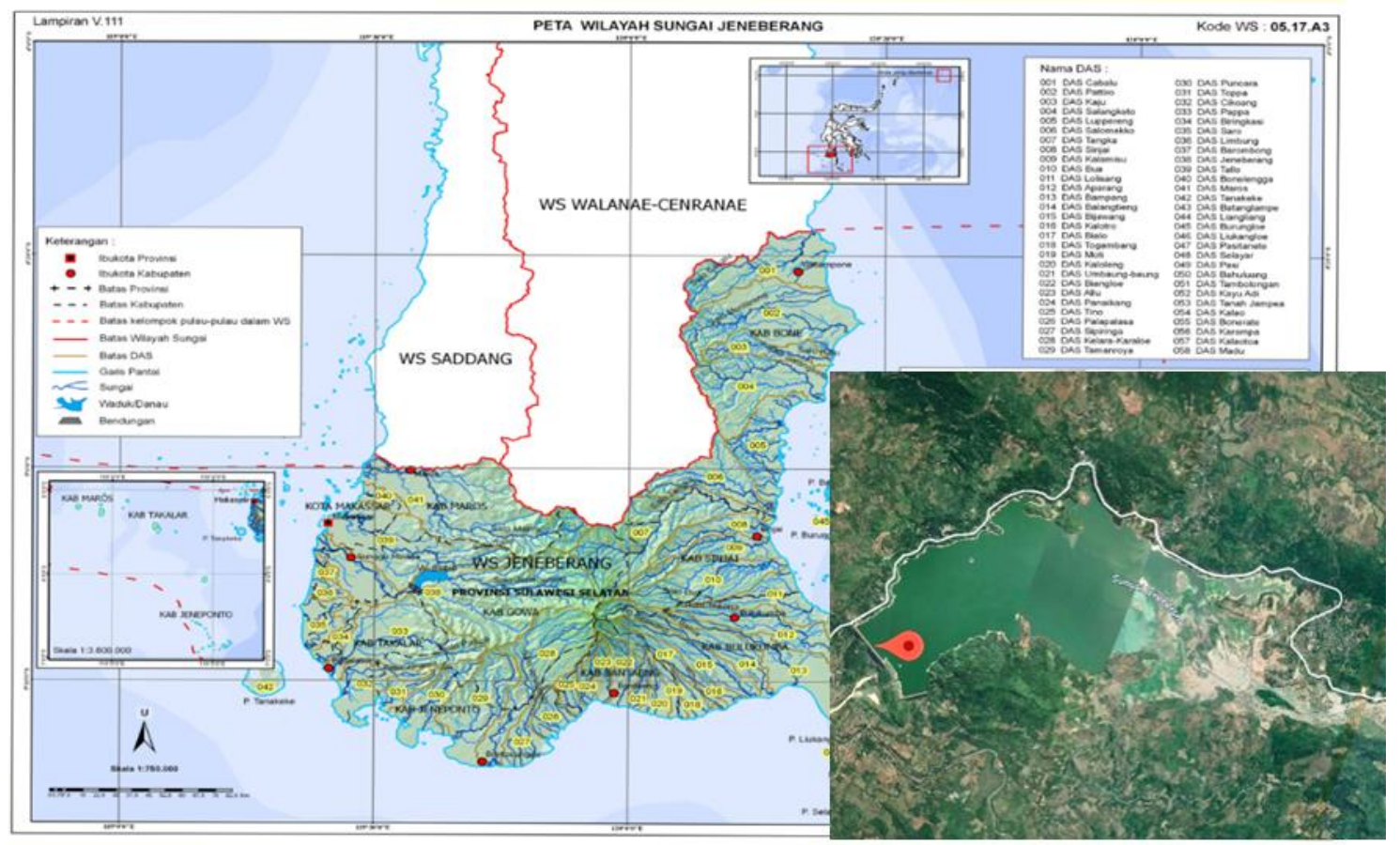

Gambar 1. Lokasi penelitian

Dalam perkembangannya telah terjadi penurunan pemanfaatan fungsi layanan waduk akibat adanya perubahan kondisi daerah tangkapan waduk, yang disebabkan oleh erosi akibat perubahan pemanfaatan lahan dan juga terjadinya longsor pada dinding Kaldera Gunung Bawakaraeng pada tahun 2004 yang lalu. Volume sedimen yang cukup besar akibat longsor, mengalir ke hilir bila intensitas curah hujan tinggi yang mengakibatkan peningkatan volume sedimen dalam Waduk Bili-bili dan terjadi pendangkalan disekitar aliran sungai sampai ke Waduk Bili-bili. Selain itu, volume sedimen dalam Waduk Bili-bili semakin bertambah banyak akibat terjadinya banjir pada bulan januari yang lalu. Dari hasil pengukuran pada tahun 2017, pada elevasi +99.5 m (muka air normal), kapasitas waduk dari 347.81 juta $\mathrm{m}^{3}$ berkurang menjadi 239.76 juta $\mathrm{m}^{3}$ selama 20 tahun. Sehingga total volume sedimen sampai tahun 2017 sebanyak 108.050 juta m3. Jika hal ini terus berlanjut, maka sisa usia guna Waduk Bili-bili tidak akan efektif.

Tujuan dari penelitian ini adalah untuk mengetahui besar volume sedimen yang ada dalam Waduk Bilibili, Kabupaten Gowa, Provinsi Sulawesi Selatan pada tahun 2019.

Berdasarkan Laporan Bili-Bili Multipurpose Dam Project, CTI Engineering Co. LTD in assc. with PT. Indra Karya and PT. Exsa International, Februari 1988 ,

angkutan sedimen untuk Bendungan Bili-Bili direncanakan sebesar $1500 \mathrm{m3} / \mathrm{km} 2 /$ tahun yang setara dengan laju sedimentasi $1.5 \mathrm{~mm} /$ tahun. Total volume sedimen selama umur rencana waduk yaitu
50 tahun adalah 29 juta $\mathrm{m}^{3}$, kapasitas tampungan mati sebesar 12 juta $\mathrm{m}^{3}$ pada elevasi +65.00 .

Bendungan Bili-Bili membendung Sungai Jeneberang di Desa Bili-Bili, Kecamatan Bontomarannu dan juga menggenangi sebagian Desa Moncongloe Kecamatan Manuju serta Kelurahan Bontoparang Kecamatan Parangloe, di mana semua kecamatan tersebut di atas berada di Kabupaten Gowa, Provinsi Sulawesi Selatan. Lokasi Bendungan Bili-Bili $\pm 30 \mathrm{~km}$ di sebelah Timur Kota Makassar dan $\pm 31 \mathrm{~km}$ dari muara Sungai Jeneberang, dengan posisi geografis $5^{\circ} 15^{\prime}$ LS dan $119^{\circ} 37^{\prime}$ BT (sumber: PT. Wahana Krida Konsulindo, Laporan Sedimentasi Waduk, 2018).

Beberapa penelitian sejenis yaitu dengan menggunakan echosounder selama kurun waktu 2012-2016, Waduk Cacaban terjadi penurunan volume $668.244,50 \mathrm{~m}^{3}$ [1], pengendapan dan pendangkalan berpengaruh terhadap kapasitas tampungan waduk [2], terdapat jenis sedimen pasir, lanau, dan lempung di perairan Teluk Awur Visualisasi peta persebaran sedimen menggunakan laju sedimentasi yang diperoleh dengan metode USLE adalah sebesar $492.34 \mathrm{~m} 3 /$ tahun, sedangkan metode pengukuran langsung sebesar 435.38 m3/tahun [4], Perhitungan sedimentasi Waduk Sermo berdasarkan Metode USLE diperoleh sedimentasi di Waduk Sermo sebesar 380.837 ton/th atau setara dengan $141.047 \mathrm{m3} /$ th dengan umur layan waduk sebesar 29,28 Tahun, jauh dari usia rencana waduk yang mencapai 50 tahun.[5]. 
Tabel 1. Volume endapan sedimen sampai Tahun 2018

\begin{tabular}{|c|r|r|r|r|r|r|}
\hline \multirow{2}{*}{ Elevasi } & \multicolumn{2}{|c|}{ Desain } & \multicolumn{2}{c|}{2018} & \multicolumn{2}{c|}{ Perbedaan } \\
\cline { 2 - 7 } & \multicolumn{1}{|c|}{ Luas } & \multicolumn{1}{c|}{ Volume } & \multicolumn{1}{c|}{ Luas } & Volume & \multicolumn{1}{c|}{ Luas } & \multicolumn{1}{c|}{ Volume } \\
\hline \hline$(\mathrm{m})$ & \multicolumn{1}{c|}{$\mathrm{km}^{2}$} & juta $\mathrm{m}^{3}$ & \multicolumn{1}{c|}{$\mathrm{km}^{2}$} & \multicolumn{1}{c|}{ juta $\mathrm{m}^{3}$} & \multicolumn{1}{c|}{$\mathrm{km}^{2}$} & juta $\mathrm{m}^{3}$ \\
\hline \hline 50 & 0.000 & 0 & 0.000 & 0 & 0.000 & 0.000 \\
54 & 0.461 & 0.461 & 0.000 & 0 & 0.461 & 0.461 \\
56 & 0.844 & 1.768 & 0.000 & 0 & 0.844 & 1.768 \\
58 & 1.200 & 3.812 & 0.000 & 0 & 1.200 & 3.812 \\
60 & 1.571 & 6.584 & 0.000 & 0 & 1.571 & 6.584 \\
62 & 1.966 & 10.122 & 0.000 & 0 & 1.966 & 10.122 \\
64 & 2.493 & 14.582 & 0.366 & 0.259 & 2.127 & 14.323 \\
66 & 3.069 & 20.144 & 1.112 & 1.768 & 1.957 & 18.376 \\
68 & 3.570 & 26.786 & 1.801 & 4.676 & 1.769 & 22.110 \\
70 & 4.102 & 34.456 & 2.357 & 8.838 & 1.745 & 25.618 \\
75 & 5.737 & 59.056 & 3.431 & 23.388 & 2.306 & 35.668 \\
80 & 8.074 & 93.586 & 4.290 & 42.471 & 3.784 & 51.115 \\
85 & 10.546 & 140.136 & 7.260 & 71.745 & 3.286 & 68.391 \\
90 & 13.512 & 200.281 & 10.380 & 116.135 & 3.132 & 84.146 \\
95 & 15.604 & 273.071 & 13.173 & 174.967 & 2.431 & 98.104 \\
99.5 & 17.412 & 347.812 & 15.803 & 239.764 & 1.609 & 108.048 \\
100 & 17.613 & 356.568 & 16.174 & 247.758 & 1.439 & 108.810 \\
103 & 19.343 & 413.732 & 18.929 & 300.886 & 0.414 & 112.846 \\
\hline
\end{tabular}

Dari tabel 1, pada elevasi +99.5 m (muka air normal), kapasitas waduk dari 347.81 juta $\mathrm{m}^{3}$ berkurang menjadi 239.76 juta $\mathrm{m}^{3}$ selama 20 tahun. Sehingga total volume sedimen sebanyak 108.050 juta $\mathrm{m}^{3}$, serta laju sedimen sebanyak 2.647 juta $\mathrm{m}^{3}$.

Profil memanjang sesuai alur sungai berdasarkan peta topografi awal tahun 1997, pengukuran terdahulu dan pengukuran tahun 2018 saat ini ditampilkan pada Gambar 2.

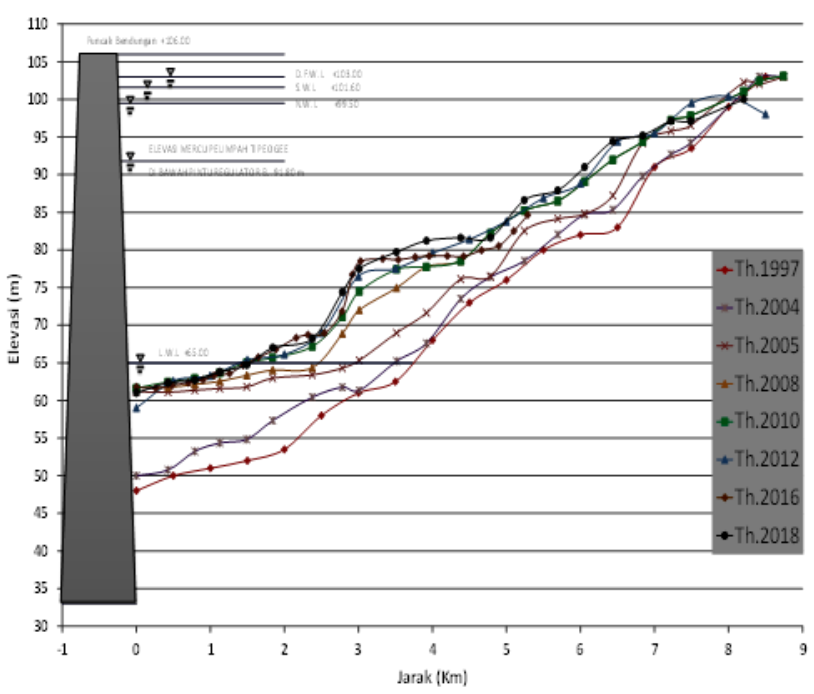

Gambar 2. Profil memanjang endapan sedimen Tahun 1997 sampai tahun 2018

\section{METODE}

\section{Volume Sedimen}

Volume sedimen dapat dihitung dengan rumus:

$\mathrm{V} 1=(\mathrm{A} 1+\mathrm{A} 2) / 2 \times \mathrm{L}$

Vtotal $=\mathrm{V} 1+\mathrm{V} 2$

Sehingga:
Vt $\quad=$ Volume Total Sedimen $\left(\mathrm{m}^{3}\right)$
V1 = Volume Sedimen antara Cross 1 dan $s 2$ $\left(\mathrm{m}^{3}\right)$

$\begin{array}{ll}\text { A1 } & =\text { Luas Area Sedimen pada Cross } 1\left(\mathrm{~m}^{2}\right) \\ \text { A2 } & =\text { Luas Area Sedimen pada Cross } 2\left(\mathrm{~m}^{2}\right) \\ \mathrm{L} & =\text { Jarak Cross }(\mathrm{m})\end{array}$

\section{Echosounder}

Echosounder adalah alat untuk mengukur kedalaman air dengan mengirimkan tekanan gelombang dari permukaan air kedasar air dan mencatat waktu sampai Echosounder kembali dari dasar air. Pada sungai yang lebar dan dalam, pengukuran tampang lintang dapat dilakukan dengan menggunakan Echosounder. Selain itu alat ini juga dapat digunakan untuk mengukur bathimetri (kedalaman) laut (Bambang Triatmojo, Hidrologi Terapan, edisi kedua).

Cara kerja Echosounder didasarkan pada prinsip:

a) Air merupakan media yang baik untuk perambatan gelombang suara dengan kecepatan \pm $1435 \mathrm{~m} /$ det.

b) Gelombang suara dapat dipantulkan dengan baik oleh dasar sungai.

Alat Echosounder dipasang pada dasar kapal atau dihantung pada sisi kapal. Alat tersebut memancarkan getaran suara yang merambat ke dasar sungai, dan kemudian dipantulkan kembali. Gelombang pantulan tersebut diterima dan dicatat oleh alat. Dengan waktu antara pemancaran dan penerimaan getaran dapat memberikan kedalaman air yang kemudian direkam pada kertas pencatat. Dari alat ini dapat diperoleh hasil profil dasar sungai secara kontinyu.

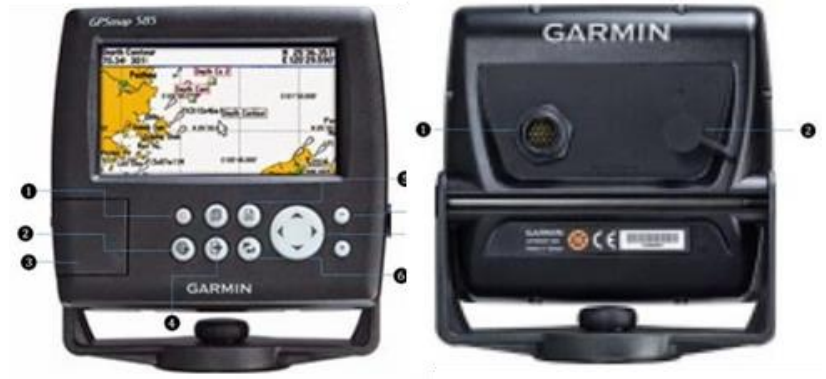

Gambar 3. Alat Echosounder garmin 585

Dalam pengukuran ini, digunakan acuan dari patok tetap yang sudah ada dalam Waduk Bili-bili dengan jarak masing-masing 50 meter.

Adapun metode kerja dari penelitian ini yaitu:

1. Pengukuran elevasi dasar waduk dengan Echosounder

Pada dasarnya pengukuran dengan Echosounder adalah pengukuran secara melintang (cross section). Pengukuran kedalaman dilakukan dengan metode pantulan gelombang ultrasonik yang dipancarkan secara tegak lurus permukaan air kedasar oleh Echosounder dan kemudian gelombang 
tersebut akan dipantulkan kembali. Langkah-langkah dalam melakukan pengukuran dengan Echosounder sebagai berikut:

1) Menentukan titik-titik pengukuran beserta jarak tiap titik dengan mengacu pada titik yang telah ada dari pengukuran sebelumnya.

2) Memasang alat Echosounder pada perahu.

3) Alat Echosounder dioperasikan diatas perahu, yang bergerak perlahan-lahan dari titik awal sampai akhir yang sesuai dengan jalur pengukuran yang telah ditentukan.

4) Pengukuran dilakukan dengan menggunakan alat Echosounder GARMIN tipe GPSMAP 580 / 585 dengan jarak antar patok $50 \mathrm{~m}$ dan kecepatan Speedboat $5-10 \mathrm{~km} / \mathrm{jam}$ agar data yang dihasilkan lebih akurat.

5) Pengukuran dilakukan secara zig-zag dari patok 1 ke patok 2 dengan jarak $50 \mathrm{~m}$, dan dilanjutkan kepatok berikutnya.

6) Dari hasil pengukuran dengan Echosounder akan diperoleh data seperti: titik-titik koordinat, kedalaman air dan tinggi muka air.

\section{Pemetaan dasar waduk hasil pengukuran} Echosounder

Setelah diperoleh data dari hasil pengukuran dengan Echosounder, maka selanjutnya membuat peta elevasi dasar waduk Bili-bili yang sesuai dengan hasil pengukuran.

3. Overlay peta waduk pada pengukuran terakhir tahun 2017 dan hasil pengukuran tahun 2019

Overlay ini dilakukan untuk membandingkan elevasi daerah genangan Waduk Bili-bili pada kondisi pengukuran terakhir dengan elevasi daerah genangan Waduk Bili-bili yang dibuat berdasarkan hasil pengukuran dengan Echosounder pada kondisi saat ini. Perbandingan ini digunkanan untuk melihat seberapa besar pertambahan sedimen dalam Waduk Bili-bili pada kondisi saat ini akibat bertambahnya sedimen dalam Waduk Bili-bili.

4. Pembuatan potongan memanjang dan melintang daerah genangan waduk.

Pembuatan potongan memanjang dan melintang dilakukan berdasarkan hasil overlay daerah genangan waduk pada pengukuran terakhir tahun 2017 dengan daerah genangan waduk pada pengukuran 2019. Pembuatan potongan memanjang bertujuan untuk melihat penyebaran sedimen yang ada dalam Waduk Bili-bili, Kabupaten Gowa. Sedangkan pembuatan potongan melintang (cross section) bertujuan untuk melihat seberapa luas sedimen yang ada didalam Waduk Bili-bili, Kabupaten Gowa.
5. Perhitungan luas penampang endapan atau sedimen.

Perhitungan luas penampang endapan atau sedimen dilakukan dengan cara perhitungan pada tiap cross section. Pembuatan cross section ini dilakukan setelah pemetaan dasar waduk hasil pengukuran dengan Echosounder yang telah dioverlay dengan pemetaan hasil pengukuran sebelumnya.

\section{Perhitungan volume total sedimen}

Perhitungan volume total sedimen merupakan tujuan dari penelitian ini. Hasil akhir dari penelitian ini yaitu berupa peta elevasi kontur Waduk Bili-bili pada kondisi saat ini (tahun 2019) dan mengenai total volume sedimen dan pertambahan dari tahun 2017 sampai tahun 2019 dalam Waduk Bili-bili, Kabupaten Gowa.

\section{HASIL DAN PEMBAHASAN}

Hasil pengolahan data dari pengukuran ini meliputi:

Pengukuran Elevasi Dasar Waduk Bili-bili, Kabupaten Gowa dengan alat Echosounder

Dalam penelitian ini, hasil dari pengukuran yang dilakukan dengan menggunakan Echosounder berupa koordinat $X$, kooordinat $Y$ dan Elevasi muka air dapat dilihat pada Tabel 1. dalam lampiran.

\section{Pemetaan Dasar Waduk Hasil Pengukuran dengan Echosounder}

Setelah mendapatkan hasil pengukuran berupa koordinat $X$, koordinat $Y$ dan elevasi muka air, selanjutnya melakukan pemetaan dasar waduk berdasarkan data yang telah didapatkan. Jalur-jalur pengukuran yang dimulai dari patok 1 - 13 dengan mengikuti acuan patok pada pengukuran tahun 2017.

Overlay Peta Elevasi Waduk Bili-bili, Kabupaten Gowa Tahun 2017 dan Peta Elevasi Waduk Bilibili, Kabupaten Gowa Tahun 2019 (Hasil Pengukuran)

Overlay peta elevasi waduk yaitu penggabungan dari kedua gambar tahun 2017 dan tahun 2019. Gambar ini akan digunakan untuk pembuatan potongan melintang (cross section). Pembuatan potongan melintang ini mengikuti titik koordinat pada pembagian sebelumnya pada tahun 2017. Berikut ini adalah gambar overlay dari kedua peta (tahun 2017 dan tahun 2019) beserta nomor koordinat pembagian potongan melintang (cross section).

\section{Penggambaran Potongan Memanjang dan Melintang Daerah Genangan Waduk Bili-bili, Kabupaten Gowa}

Perhitungan Luas Penampang Endapan Sedimen dan Perhitungan Volume Total Sedimen dalam Waduk Bili-bili, Kabupaten Gowa 
Hasil perhitungan luas penampang endapan sedimen dan volume total sedimen dapat dilihat pada tabel berikut:

Tabel 2. Hasil perhitungan volume total sedimen tahun 2019

\begin{tabular}{ccccc}
$\begin{array}{c}\text { No. } \\
\text { Cross }\end{array}$ & A $\left(\mathrm{m}^{2}\right)$ & $\begin{array}{c}\text { Jarak Tiap } \\
\text { Segmen }\end{array}$ & $\begin{array}{c}\text { Volume } \\
\text { Sedimen }\end{array}$ & $\begin{array}{c}\text { Volume Total } \\
\text { Sedimen }\end{array}$ \\
\cline { 1 - 4 } & & $\left.\mathbf{m}^{2}\right)$ & juta $\left(\mathbf{m}^{3}\right)$ & juta $\left(\mathbf{m}^{3}\right)$ \\
\cline { 1 - 4 } $\mathbf{1}$ & 2134.111 & 258.94 & 3237310 & 3237310 \\
\cline { 1 - 2 } $\mathbf{2}$ & 22870.211 & & & \\
\cline { 1 - 2 } $\mathbf{3}$ & 56976.638 & 131.97 & 5268694 & 8506004 \\
\hline $\mathbf{4}$ & 16496.515 & 467.59 & 17177656 & 25683660 \\
\hline $\mathbf{5}$ & 36493.491 & 445.60 & 11806173 & 37489833 \\
\hline $\mathbf{6}$ & 6717.192 & 1250.19 & 27010782 & 64500615 \\
\hline $\mathbf{7}$ & 29087.498 & 474.26 & 8490366 & 72990981 \\
\hline $\mathbf{8}$ & 7080.076 & 510.33 & 9228699 & 82219680 \\
\hline $\mathbf{9}$ & 11920.570 & 804.73 & 7645195 & 89864875 \\
\hline $\mathbf{1 0}$ & 21997.812 & 711.05 & 12058833 & 101923708 \\
\hline $\mathbf{1 1}$ & 5291.665 & 619.12 & 8447731 & $\mathbf{1 1 0 3 7 1 4 3 8}$ \\
\hline
\end{tabular}

Total Laju Sedimen dalam Waduk Bili-bili Tahun 2017 sampai 2019

Total Laju Sedimen 2017 - $2019=$ Total Volume Sedimen Tahun 2019 - Total Volume Sedimen sampai Tahun 2017

$$
\begin{aligned}
& =110.371 \text { juta } \mathrm{m}^{3}-108.050 \text { juta } \mathrm{m}^{3} \\
& =2.321 \text { juta } \mathrm{m}^{3}
\end{aligned}
$$

\section{Pembahasan}

Dari hasil pengukuran dan perhitungan diperoleh total volume sedimen dalam Waduk Bili-bili, Kabupaten Gowa pada tahun 2019 sebanyak 110.371 juta $\mathrm{m}^{3}$. Dimana pada pengukuran tahun 2017 total volume sedimen sebanyak 108.050 juta $\mathrm{m}^{3}$. Total laju sedimen pada tahun 2017 sampai tahun 2019 sebanyak 2.321 juta $\mathrm{m}^{3}$. Perbandingan elevasi dari

\section{DAFTAR PUSTAKA}

[1] Anggara WWS dan Nuny S, 2016, "Studi Perubahan Volume Waduk Cacaban dengan Survei Pemeruman Waduk", Jurnal Teknik Pengairan: Journal of Water Resources Engineering Vol.7, no.2.

[2] Welstien H, Indratmo S, Arwin S, dan Sri L, 2015, "Analisis Volume Sedimen yang Mengendap Setelah T-Tahun Waduk Beroperasi (Studi Kasus: Waduk Cirata), Jurnal Teknik Sipil, Vol.22, no.3, doi: 10.5614\%2Fjts.2015.22.3.7 tahun 1997 sampai tahun 2019 dapat dilihat pada Gambar 4. berikut:

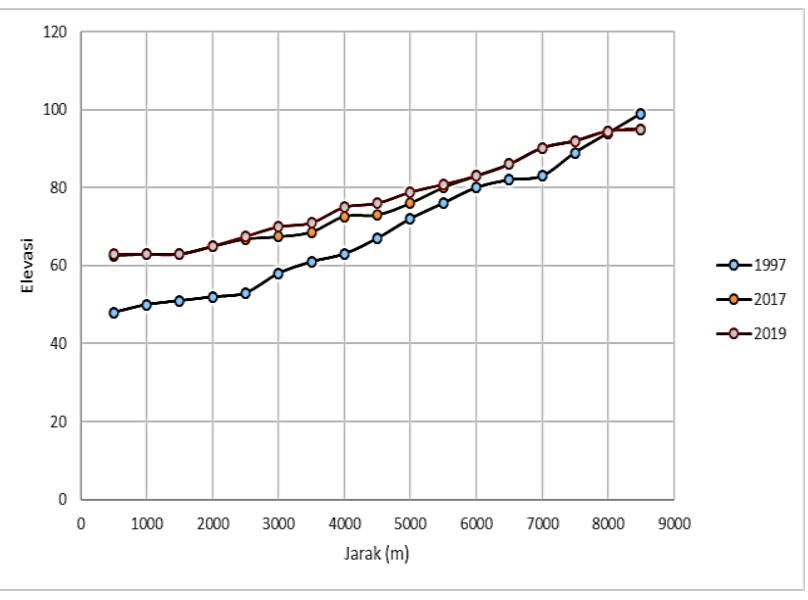

Gambar 4. Grafik perbandingan elevasi dari tahun 1997 sampai 2019

Dari grafik dapat dilihat bahwa perbandingan elevasi dari tahun 1997, tahun 2017 dan tahun 2019 selalu mengalami kenaikan. Hal ini disebabkan oleh pertambahan sedimen yang masuk dalam waduk akibat tingginya curah hujan pada saat musim hujan. Namun pada tahun 2019, hanya sebagian yang mengalami kenaikan karena pengukuran tidak dilakukan pada semua area, sehingga dipakai elevasi pada saat pengukuran terakhir yaitu tahun 2017 .

\section{KESIMPULAN}

Dari hasil penelitian, diperoleh kesimpulan bahwa hasil perhitungan sedimen dari tahun 1997 sampai tahun 2019 dalam Waduk Bili-bili, Kabupaten Gowa diperoleh total volume sedimen sebanyak 110.371 juta $\mathrm{m}^{3}$. Dimana pada pengukuran tahun 2017 total volume sedimen hanya sebanyak 108.050 juta $\mathrm{m}^{3}$. Total laju sedimen pada tahun 2017 sampai tahun 2019 sebanyak 2.321 juta $\mathrm{m}^{3}$.

[3] S. Badaruddin, A. Azis, dan I. Mutiara, 2018, "Aplikasi Metode Analitis dan Pemodelan Numerik Untuk Prediksi Intrusi Air Laut di Kabupaten Jeneponto", in Seminar Hasil Penelitian (SNP2M).

[4] R. Setiyanto, N. Djarwanti, dan A. P. Rahmadi,2014, "Analisis Struktur BEndungan (Studi Kasus Konstruksi Embung Gamang)" , Matriks Teknik Sipil. Vol.2, no.4, doi: https://doi.org/10.20961/mateksi.v2i4.37362

[5] E. Sriyono dan N. Achmad, 2016, "Pengaruh Erosi dan Sedimentasi Terhadap Pelestarian Layanan Umur Manfaat Waduk", Jurnal Teknik, Vol.6, no.1, ISSN 2088 - 3676 